\title{
Methylmalonyl-CoA Epimerase Deficiency Mimicking Propionic Aciduria
}

\author{
Lenaig Abily-Donval 1,2, Stéphanie Torre ${ }^{1}$, Aurélie Samson ${ }^{3}$, Bénédicte Sudrié-Arnaud ${ }^{3}$, \\ Cécile Acquaviva ${ }^{4}$, Anne-Marie Guerrot ${ }^{5}$, Jean-François Benoist ${ }^{6}$, Stéphane Marret ${ }^{1,2}$, \\ Soumeya Bekri ${ }^{2,3}$ and Abdellah Tebani ${ }^{2,3, * \text { (D) }}$ \\ 1 Department of Neonatal Pediatrics and Intensive Care, Rouen University Hospital, 76000 Rouen, France; \\ lenaig.abily-donval@chu-rouen.fr (L.A.-D.); Stephanie.Torre@chu-rouen.fr (S.T.); \\ stephane.marret@chu-rouen.fr (S.M.) \\ 2 Normandie Université, UNIROUEN, CHU Rouen, INSERM U1245, 76000 Rouen, France; \\ soumeya.bekri@chu-rouen.fr \\ 3 Department of Metabolic Biochemistry, Rouen University Hospital, 76000 Rouen, France; \\ samson.aurelie@gmail.com (A.S.); B.Sudrie-Arnaud@chu-rouen.fr (B.S.-A.) \\ 4 Service Maladies Héréditaires du Métabolisme, Centre de Biologie et Pathologie Est, \\ Centre Hospitalier Universitaire de Lyon et UMR, 69677 Bron, France; \\ cecile.acquaviva-bourdain@chu-lyon.fr \\ 5 Department of Genetics, Rouen University Hospital, 76000 Rouen, France; \\ Anne-Marie.Guerrot@chu-rouen.fr \\ 6 Hormonology and Biochemistry Department, Robert Debré Hospital, AP-HP, 75019 Paris, France; \\ jean-francois.benoist@aphp.fr \\ * Correspondence: abdellah.tebani@chu-rouen.fr; Tel.: +33-2-3288-8124
}

Received: 20 October 2017; Accepted: 30 October 2017; Published: 1 November 2017

\begin{abstract}
Methylmalonyl-CoA epimerase (MCE) converts D-methylmalonyl-CoA epimer to L-methylmalonyl-CoA epimer in the propionyl-CoA to succinyl-CoA pathway. Only seven cases of MCE deficiency have been described. In two cases, MCE deficiency was combined with sepiapterin reductase deficiency. The reported clinical pictures of isolated MCE are variable, with two asymptomatic patients and two other patients presenting with metabolic acidosis attacks. For combined MCE and sepiapterin reductase deficiency, the clinical picture is dominated by neurologic alterations. We report isolated MCE deficiency in a boy who presented at five years of age with acute metabolic acidosis. Metabolic investigations were consistent with propionic aciduria (PA). Unexpectedly, propionyl-CoA carboxylase activity was within the reference range. Afterward, apparently intermittent and mild excretion of methylmalonic acid (MMA) was discovered. Methylmalonic pathway gene set analysis using the next-generation sequencing approach allowed identification of the common homozygous nonsense pathogenic variant (c.139C > T-p.Arg47*) in the methylmalonyl-CoA epimerase gene (MCEE). Additional cases of MCE deficiency may help provide better insight regarding the clinical impact of this rare condition. MCE deficiency could be considered a cause of mild and intermittent increases in methylmalonic acid.
\end{abstract}

Keywords: methylmalonyl-CoA epimerase; methylmalonic aciduria; propionic aciduria

\section{Introduction}

Isolated methylmalonic aciduria (MMA) is mainly caused by methylmalonyl-CoA mutase or deficiency of its co-factor, adenosylcobalamin. MMA onset usually occurs during the neonatal period with clinical intoxication signs such as hypotonia, encephalopathy, seizures, vomiting, and failure to thrive. Recently, guidelines have been issued for their management [1]. Of note, occurrences of atypical methylmalonic aciduria due to methylmalonyl-CoA epimerase (MCE) deficiency are less frequent. 
MCE converts D-methylmalonyl-CoA epimer to L-methylmalonyl-CoA epimer, which is the substrate of methylmalonyl-CoA mutase (Figure 1) [2]. The clinical picture of this entity is variable, spanning from acute metabolic decompensation to no symptoms. However, few cases of MCE deficiency have been described to date [3-7]. We report a case of MCE deficiency presenting with acute metabolic acidosis and biochemical features of propionic aciduria.

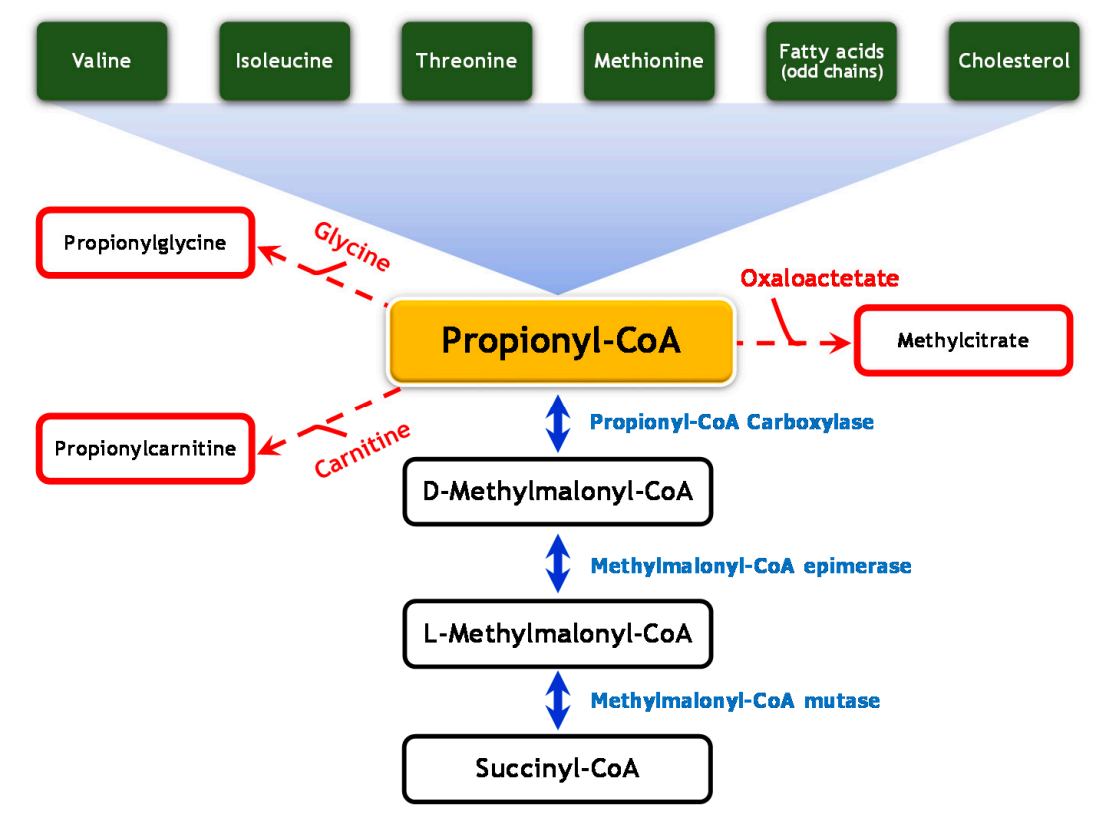

Figure 1. Metabolism of propionic acid. The catabolism of several amino acids (valine, isoleucine, threonine, and methionine) as well as odd chain fatty acids and cholesterol leads to the production of propionyl-CoA. When propionyl-CoA accumulates, other components-such as methylcitrate (formed by condensation of propionyl-CoA with oxaloacetate), propionylglycine, and propionylcarnitine-are found in urine and blood.

\section{Case Report}

A boy was born to non-consanguineous parents with no specific family history. The birth was uneventful at 38 weeks of gestation. Motor development was normal, but the boy developed a moderate language delay. Frequent catabolism episodes with vomiting were noticed without decompensation. At five years of age, he presented with acute vomiting and feeding intolerance. Physical examination showed dehydration with severe signs such as tachycardia, polypnea, and hypotonia. Echocardiography and cerebral magnetic resonance imaging (MRI) results were normal. There was no kidney failure. Blood assessment revealed hydroelectrolyte balance alterations with metabolic acidosis $\left(\mathrm{pH}=7.08\right.$, bicarbonates $=7.3 \mathrm{mmol} / \mathrm{L}$, normal lactic acid, $\left.\mathrm{PCO}_{2}=25 \mathrm{mmHg}\right)$ and hyperammmoniemia $(100 \mu \mathrm{mol} / \mathrm{L})$. Glycemia was normal. Ketone concentrations were high in urine samples. Blood count was unremarkable. Metabolic investigation results were consistent with propionic aciduria, with a large increase in plasmatic propionylcarnitine $(17.5 \mu \mathrm{mol} / \mathrm{L} ; \mathrm{N}<0.75)$, undetectable methylmalonylcarnitine (Figure 2A), and high urinary excretion of 3-hydroxypropionate (Figure 2B) and methylcitrate. Unexpectedly, propionyl-CoA carboxylase activity was within the reference range after assessment using cultured fibroblasts. Urinary organic acids analyses results determined apparently intermittent and mild excretion of methylmalonic acid. Fifteen assessments were performed, with results ranging from undetectable (once during the initial decompensation) to $212 \mu \mathrm{mol} / \mathrm{mmol}$ creatinine, with a mean of 69 and a median of 44 (Figure 2C). Increased urinary methylmalonic acid steered the diagnosis toward methylmalonic aciduria. Propionylcarnitine was constantly elevated in plasmatic acylcarnitine profiles, whereas traces of methylmalonylcarnitine were 
detected once. The plasmatic glycine concentration was within the reference range. Methylmalonic pathway gene set analysis using the next-generation sequencing (NGS) approach allowed identification of a homozygous nonsense variant (c.139C > T-p.R47*) in the methylmalonyl-CoA epimerase gene (MCEE-NM_032601.3). A hypoprotidic diet (1 g/ $\mathrm{kg} /$ day) was introduced, as well as carnitine and vitamin B12 supplementation to enhance MMA metabolism. During follow-up, moderate language and attentional difficulties were noticed; however, the patient had satisfactory academic results in school.
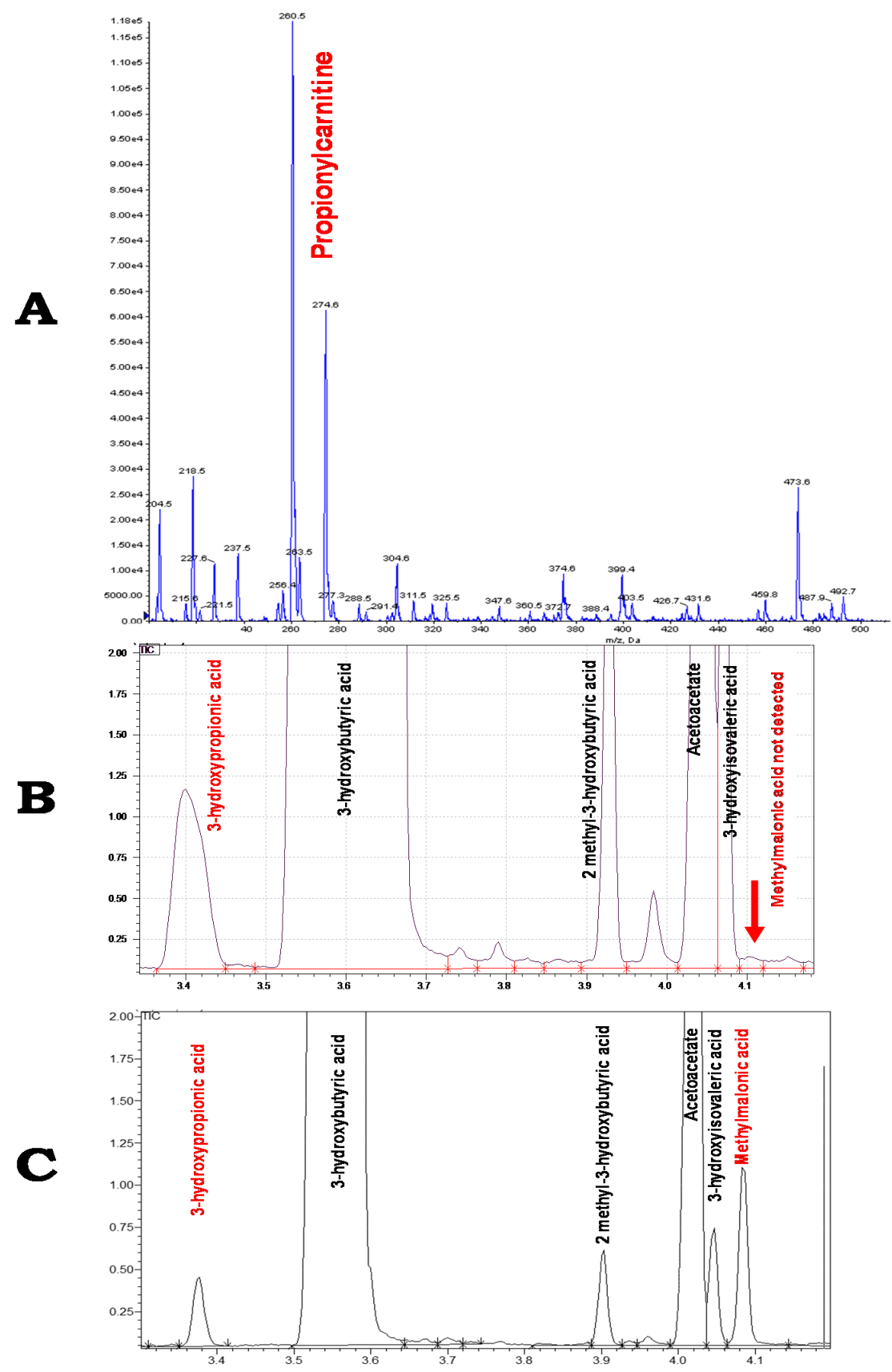

Figure 2. Acylcarnitine and urinary organic acid profiles. (A) Acylcarnitine profile using LC-MS/MS showing an elevation in propionylcarnitine following the acute metabolic crisis; (B) Acid organic profile using GC-MS presenting a high concentration of 3-hydroxypropionic acid with no methylmalonic acid detection; (C) Organic acid profile presenting a moderate increase of 3-hydroxypropionic acid and methylmalonic acid concentrations during follow-up, distant from any decompensation. $1.00 \mathrm{e}^{4}=10,000 ; 1.00 \mathrm{e}^{5}=100,000$. 


\section{Discussion}

The diagnosis of MCE deficiency may be very challenging. In our case, the initial biochemical and clinical features were consistent with propionic aciduria (PA). Methylmalonic acid urinary excretion was apparently intermittent and mild and was not observed during the decompensation episode. Of note, the absence of MMA may be due to the lack of sensitivity of the organic acid assessment using gas chromatography/mass spectrometry. This drawback may be circumvented by using dedicated sensitive methods for MMA such as stable isotope dilution. NGS analysis of methylmalonic pathway genes allowed confirmation of MCE deficiency. MCE was described by Mazumder et al. in 1961 [2] as an enzyme converting D-methylmalonyl-CoA epimer to L-methylmalonyl-CoA epimer in the propionyl-CoA to succinyl-CoA pathway. The human gene MCEE, which codes for methylmalonyl CoA epimerase, was identified in 2001 [8]. Only seven cases of MCE deficiency have been described to date (Table 1), and in two cases MCE deficiency was combined with sepiapterin reductase deficiency $[3,6]$. The variant c.139C > T-p.R47* is frequent and was found during the homozygous state in six cases (including this present case) and during the heterozygous state in one case [7]. Concerning isolated MCE deficiency, Dobson et al. described the first two patients in 2006 [4]. The proband (P1) failed to thrive and was treated for severe gastro-oesophageal reflux. He presented at 13.5 months with severe metabolic acidosis. Organic urinary acids revealed methylmalonic and methylcitric acid elevation. This patient was treated with vitamin B12 infusions and was placed on a normoproteic diet. At age 12.5 years, growth and psychomotor development were satisfactory. His older sister (P2) presented with hydrocephalus at one year of age. After surgical treatment, development was normal. The urinary concentration of methylmalonic acid was elevated ( $95 \mu \mathrm{mol} / \mathrm{mmol}$ creatinine); therefore, a protein-restricted diet and sporadic vitamin B12 treatment were undertaken [4]. Isolated MCE deficiency was not associated with neurological impairment in patients P1, P2, P3, P5, and P6 (our case) (Table 1), who had MCE deficiency combined with sepiapterin reductase (SPR) deficiency. However, P7 and P8 also had neurological deterioration. These neurological features were related to SPR deficiency and improved with L-DOPA and 5HTP treatment [6]. Grandinger et al. described a three-year-old patient (P4) with dysarthria, mild spastic paraparesis, and ataxia related to isolated MCE deficiency; however, they did not report the SPR molecular study findings to confirm the exclusive MCE association with the neurological alterations [5]. 
Table 1. Clinical, biochemical, and molecular characteristics of the described MCE patients.

\begin{tabular}{|c|c|c|c|c|c|c|c|c|c|c|}
\hline \multirow{2}{*}{ Patient } & \multirow{2}{*}{ Isolated MCE } & \multirow{2}{*}{$\begin{array}{c}\text { Age at } \\
\text { Diagnosis }\end{array}$} & \multirow{2}{*}{$\begin{array}{c}\text { Acute } \\
\text { Metabolic } \\
\text { Acidosis }\end{array}$} & \multirow{2}{*}{$\begin{array}{l}\text { Psychomotor } \\
\text { Development }\end{array}$} & \multirow{2}{*}{$\begin{array}{c}\text { Language } \\
\text { Development }\end{array}$} & \multirow{2}{*}{$\begin{array}{l}\text { Neurological } \\
\text { Impairment }\end{array}$} & \multirow{2}{*}{$\begin{array}{c}\text { Urinary MMA } \\
\text { Concentration } \\
(\mu \mathrm{mol} / \mathrm{mmol} \text { Creatinine) }\end{array}$} & \multicolumn{2}{|c|}{ MCEE Variants } & \multirow{2}{*}{ Reference } \\
\hline & & & & & & & & Allele 1 & Allele 2 & \\
\hline P1 & Yes & 13.5 months & Yes & Normal & Normal & No & $180-1456$ & $\begin{array}{c}c .139 \mathrm{C}> \\
\text { T-p.Arg47* }\end{array}$ & $\begin{array}{c}\text { c.139C> } \\
\text { T-p.Arg } 47^{*}\end{array}$ & [4] \\
\hline P2 & Yes & $\begin{array}{l}14 \text { years (patient } \\
1 \text { sibling) } \\
\text { Asymptomatic }\end{array}$ & No & Normal & Normal & No & 95-166 & $\begin{array}{c}\text { c. } 139 \mathrm{C}> \\
\text { T-p.Arg47* }\end{array}$ & $\begin{array}{c}\text { c.139C > } \\
\text { T-p.Arg47 }\end{array}$ & [4] \\
\hline P3 & Yes & $\begin{array}{l}\text { Asymptomatic } \\
\text { (patient } 8 \\
\text { sibling) }\end{array}$ & No & Normal & Normal & No & 1400 & $\begin{array}{c}\text { c. } 139 \mathrm{C}> \\
\text { T-p.Arg47* }\end{array}$ & $\begin{array}{c}\text { c.139C > } \\
\text { T-p.Arg47 }\end{array}$ & [5] \\
\hline P4 & Yes (?) & 3 years & NC & $\begin{array}{l}\text { Deteriorated } \\
\text { motor function }\end{array}$ & Dysarthria & $\begin{array}{l}\text { Mild spastic } \\
\text { paraparesis } \\
\text { Ataxia }\end{array}$ & 621 & $\begin{array}{c}\text { c.178A > } \\
\text { C-p.Lys60Gln }\end{array}$ & $\begin{array}{c}\text { c.178A > } \\
\text { C-p.Lys60Gln }\end{array}$ & [5] \\
\hline P5 & Yes & 5 years & Yes & Normal & Normal & No & $47-151$ & $\begin{array}{c}\text { c.139C > } \\
\text { T-p.Arg } 47^{*}\end{array}$ & $\begin{array}{c}\text { c.379-644A > } \\
\text { G-p.(?) }\end{array}$ & [7] \\
\hline P6 & Yes & 5 years & Yes & $\begin{array}{l}\text { Attentional } \\
\text { difficulties }\end{array}$ & Moderate delay & No & $\begin{array}{c}\text { No MMA excretion } \\
\text { during the acute } \\
\text { metabolic acidosis } \\
\text { episode; afterwards } \\
18-212\end{array}$ & $\begin{array}{c}\text { c. } 139 \mathrm{C}> \\
\text { T-p.Arg } 47^{*}\end{array}$ & $\begin{array}{c}\text { c.139C > } \\
\text { T-p.Arg47* }\end{array}$ & This study \\
\hline P7 & $\begin{array}{l}\text { Combined with } \\
\text { sepiapterin } \\
\text { reductase } \\
\text { deficiency }\end{array}$ & 2 years & No & Retardation & $\mathrm{NC}$ & Spasticity & 142 & $\begin{array}{c}\text { c.139C > } \\
\text { T-p.Arg47 }\end{array}$ & $\begin{array}{c}\text { c. } 139 \mathrm{C}> \\
\text { T-p.Arg47* }\end{array}$ & [3] \\
\hline P8 & $\begin{array}{l}\text { Combined with } \\
\text { sepiapterin } \\
\text { reductase } \\
\text { deficiency }\end{array}$ & 1 month & No & Retardation & Limited speech & $\begin{array}{c}\text { Axial hypotonia } \\
\text { Postural } \\
\text { instability } \\
\text { Oculogyric } \\
\text { crisis } \\
\text { Fatigability } \\
\text { with sleep } \\
\text { disorders }\end{array}$ & 60 & $\begin{array}{c}\text { c. } 139 \mathrm{C}> \\
\text { T-p.Arg47* }\end{array}$ & $\begin{array}{c}\text { c. } 139 \mathrm{C}> \\
\text { T-p.Arg47* }\end{array}$ & [6] \\
\hline
\end{tabular}




\section{Conclusions}

A diagnosis of MCE is quite difficult to achieve because those with asymptomatic cases (P2 and P3) and those with severe acute metabolic acidosis cases have been described (P1, P5, and P6). Our case is intriguing because the initial presentation was consistent with PA. However, the continuing metabolic follow-up led to observations of moderate and intermittent elevations of MMA. Of note, elevated concentrations of propionylcarnitine with no increase in methylmalonylcarnitine do not allow for MMA to be excluded. In conclusion, this novel case contributes to the characterization of this rare condition and may help to elucidate intermittent elevations in methylmalonic acid.

Author Contributions: Lenaig Abily-Donval gathered data and drafted the manuscript. Stéphanie Torre and Anne-Marie Guerrot performed the clinical assessment. Aurélie Samson and Bénédicte Sudrié-Arnaud gathered the biochemical data. Cécile Acquaviva performed the assessment of propionyl CoA carboxylase activity. Jean-François Benoist performed the molecular analysis. Stéphane Marret critically edited the manuscript. Soumeya Bekri critically edited and revised the manuscript. Abdellah Tebani designed and drew the figures and critically edited and revised the manuscript. All the authors approved the final version of the manuscript.

Conflicts of Interest: The authors declare no conflict of interest.

\section{References}

1. Baumgartner, M.R.; Horster, F.; Dionisi-Vici, C.; Haliloglu, G.; Karall, D.; Chapman, K.A.; Huemer, M.; Hochuli, M.; Assoun, M.; Ballhausen, D.; et al. Proposed guidelines for the diagnosis and management of methylmalonic and propionic acidemia. Orphanet J. Rare Dis. 2014, 9, 130. [CrossRef] [PubMed]

2. Mazumder, R.; Sasakawa, T.; Kaziro, Y.; Ochoa, S. A new enzyme in the conversion of propionyl coenzyme a to succinyl coenzyme a. J. Biol. Chem. 1961, 236, 53-55.

3. Bikker, H.; Bakker, H.D.; Abeling, N.G.; Poll-The, B.T.; Kleijer, W.J.; Rosenblatt, D.S.; Waterham, H.R.; Wanders, R.J.; Duran, M. A homozygous nonsense mutation in the methylmalonyl-coa epimerase gene (mcee) results in mild methylmalonic aciduria. Hum. Mutat. 2006, 27, 640-643. [CrossRef] [PubMed]

4. Dobson, C.M.; Gradinger, A.; Longo, N.; Wu, X.; Leclerc, D.; Lerner-Ellis, J.; Lemieux, M.; Belair, C.; Watkins, D.; Rosenblatt, D.S.; et al. Homozygous nonsense mutation in the mcee gene and sirna suppression of methylmalonyl-coa epimerase expression: A novel cause of mild methylmalonic aciduria. Mol. Genet. Metab. 2006, 88, 327-333. [CrossRef] [PubMed]

5. Gradinger, A.B.; Belair, C.; Worgan, L.C.; Li, C.D.; Lavallee, J.; Roquis, D.; Watkins, D.; Rosenblatt, D.S. Atypical methylmalonic aciduria: Frequency of mutations in the methylmalonyl coa epimerase gene (mcee). Hum. Mutat. 2007, 28, 1045. [CrossRef] [PubMed]

6. Mazzuca, M.; Maubert, M.A.; Damaj, L.; Clot, F.; Cadoudal, M.; Dubourg, C.; Odent, S.; Benoit, J.F.; Bahi-Buisson, N.; Christa, L.; et al. Combined sepiapterin reductase and methylmalonyl-coa epimerase deficiency in a second patient: Cerebrospinal fluid polyunsaturated fatty acid level and follow-up under 1-dopa, 5-htp and bh4 trials. JIMD Rep. 2015, 22, 47-55. [PubMed]

7. Waters, P.J.; Thuriot, F.; Clarke, J.T.; Gravel, S.; Watkins, D.; Rosenblatt, D.S.; Levesque, S. Methylmalonyl-coa epimerase deficiency: A new case, with an acute metabolic presentation and an intronic splicing mutation in the mcee gene. Mol. Genet. Metab. Rep. 2016, 9, 19-24. [CrossRef] [PubMed]

8. Bobik, T.A.; Rasche, M.E. Identification of the human methylmalonyl-coa racemase gene based on the analysis of prokaryotic gene arrangements. Implications for decoding the human genome. J. Biol. Chem. 2001, 276, 37194-37198. [CrossRef] [PubMed]

(c) 2017 by the authors. Licensee MDPI, Basel, Switzerland. This article is an open access article distributed under the terms and conditions of the Creative Commons Attribution (CC BY) license (http:/ / creativecommons.org/licenses/by/4.0/). 